\title{
Environmental friendly concrete production using municipal solid waste incineration materials
}

\author{
Z. Pavlík, M. Keppert, M. Pavlíková, P. Volfová \& R. Černý \\ Department of Materials Engineering and Chemistry, Faculty of Civil \\ Engineering, Czech Technical University in Prague, Czech Republic
}

\begin{abstract}
The building industry, especially construction materials' production, is a major user of the world's resources and together with energy production one of the most important sources of the $\mathrm{CO}_{2}$ production. Among building materials, concrete is element which is the second most consumed substance in the world, whereas only water is used in greater quantities. Apparently, almost one ton of concrete is used for each person in the world each year. From the point of view of ecological and sustainable aspects, concrete industry is now recognized as the largest consumer of natural resources and significant producer of waste. In order to preserve clean environment, there is a need for improvement of existing production technologies of concrete by transforming them into sustainable and environmentally friendly. Municipal solid waste incineration (MSWI) materials as fly ashes and bottom ashes have not dissimilar average chemical composition from that of coal fly ashes and slag from iron production. On that account one can assume possible use of MSWI materials as partial Portland cement replacement in concrete mix design or in a raw state as partial aggregate replacement. Since waste treatment represents serious problem for advanced as well as for developing countries, the use of MSWI materials in concrete production is beneficial for both ecological and financial reasons.

Three kinds of MSWI fly ashes in state "as received" were characterized and their potential use as filler in cement based mortars was tested. The motivation of this utilization was to replace part of the fine aggregate dose in the mortars. All tested ashes made the mortars properties worse; the reasons and possible solutions are discussed.
\end{abstract}

Keywords: municipal solid waste incineration, fly ash, cement mortar, aggregate replacement, porosity, strength, durability. 


\section{Introduction}

The building materials are manufactured mainly on natural basis, what has harmful effect on the living environment quality. Hence the ways of the natural sources savings are searched. One of important ways, widely applied in civil engineering for long years, is to replace natural sources with secondary materials (i.e. wastes from other processes).

The municipal solid wastes incineration (MSWI) generates worldwide significant amounts of waste materials which can be used in civil engineering. The composition of MSWI wastes is generally more complex than in case of coal ashes but MSWI ashes differ highly in dependence on technology used in particular MSWI facility and on composition of incinerated wastes. Generally the MSWI ashes can be divided to two groups; bottom ash and fly ashes. The number and character of generated fly ashes depends on the flue gas treatment technology applied in particular MSWI facility.

Beyond the ash forming oxides $\left(\mathrm{SiO}_{2}, \mathrm{Al}_{2} \mathrm{O}_{3}, \mathrm{Fe}_{2} \mathrm{O}_{3}, \mathrm{CaO}, \mathrm{MgO}\right)$ and alkalies $\left(\mathrm{Na}_{2} \mathrm{O}, \mathrm{K}_{2} \mathrm{O}\right)$ the MSWI ashes contain higher amount of trace elements, especially heavy metals. These are responsible for environmental risks; MSWI wastes have to be treated in order to reduce the leaching out of heavy metals to the environment. It is necessary to remove or immobilizate heavy metals priory to MSWI ashes land filling. The utilization of MSWI ashes as concrete admixtures combines both effects - immobilization of heavy metals and savings of natural sources in civil engineering.

The pioneering paper on utilization of MSWI ashes - namely bottom ash - in civil engineering published Pera et al. [1]. They used bottom ash in raw state and after washing in solution of $\mathrm{NaOH}$ as replacement of natural aggregates. In both cases the bottom ash reduced the concrete strength. Similar behavior observed authors of papers [2] and [3]. Generally may be stated that the bottom ash cause the strength decrease due to content of metallic aluminium particles which induce in alkaline environment the hydrogen evolution [4].

The utilization of fly ashes is possible in two roles; either as the replacement of cement or replacement of fine aggregates. Here is beneficiary the fine granulometry of fly ashes which improve the granulometry curve of aggregates mixture. Gao et al. [5] used water washed fly ash as cement replacement, the concrete strength reduction was about $40 \%$. More successful way how to reduce the negative effects of MSWI fly ashes on concrete strength is vitrification. Lee and Rao [6] used for vitrification scrap glass; the resulting material reduced the concrete strength just moderately. Lee and Li [7] melted MSWI fly ash with quartz sand in proportion leading to $\mathrm{SiO}_{2} / \mathrm{CaO}$ ratio in the resulting slag to 0.9. This slag was highly pozzolanic and could be used as full-fledged cement replacement. Obviously the vitrification procedure is highly energy consuming.

In this paper, the use of MSWI fly ashes as partial replacement of silicate aggregates in cement mortar is studied. The fly ashes are used in the raw state, without any treatment procedure in order to evaluate their effects on mortars properties and to identify the weak points of particularly studied fly ashes. 


\section{Experimental methods}

Chemical composition of fly ashes was examined by XRF spectroscopy (ARL $9400 \mathrm{XP}$, Thermo). The grading analysis was performed by standard set of sieves [8]. Particle size analysis was carried out also by laser analyser Analysette 22 MicroTec plus (Fritsch). The pore size distribution and total porosity of prepared mortars were measured by mercury intrusion porosimetry (Pascal $140+$ 440, Thermo). The bending strength of cured (28 days in RH 100\%) mortars (prismatic samples $160 \times 40$ × $40 \mathrm{~mm}$ ) was determined using the procedure described in ČSN EN 12390-5 [9]. The compressive strength was measured according to the ČSN EN 12390-3 [10] on the portions of prisms broken in flexure test; the loading area was 40 x $40 \mathrm{~mm}$. The durability of mortars was evaluated by measurement of compressive strength of mortars before and after 75 freezing/thawing cycles in water [11].

\section{Studied materials}

Three kinds of fly ashes were collected in MSWI facility Termizo in Liberec (Czech Republic). Beyond the fly ashes, the bottom ash is generated in the plant but it was not object of this study. The FA (fly ash) 1 was collected in the 2.-3. boiler pass, FA2 in 4 . boiler pass and ESP fly ash in Electrostatic precipitator. These fly ashes were used in the raw state, without any treatment procedure. Normally in this plant the fly ashes are washed by acid solution in order to remove heavy metals and then mixed with bottom ash and provided as construction material for banks and backfills.

The fly ashes were used as partial replacement of siliceous sand $(0 / 4 \mathrm{~mm})$ in mortars (Table 1). The amount of water in fly ashes containing mortars was higher in order to maintain good workability of fresh mixtures. Cement CEM I 42.5 $\mathrm{R}$ was used as binder. The mixtures were mixed in laboratory mixer and specimens were casted and then stored in environment of $100 \% \mathrm{RH}$.

Table 1: Composition of prepared mortars.

\begin{tabular}{|c|c|c|c|c|}
\hline \multirow{2}{*}{ Component } & Ref & M-FA1 & M-FA2 & M-ESP \\
\cline { 2 - 5 } & \multicolumn{4}{|c|}{$\mathrm{kg} / \mathrm{m}^{3}$} \\
\hline CEM I 42.5 R & 580 & 580 & 580 & 580 \\
\hline Sand 0/4 mm & 1750 & 1575 & 1575 & 1575 \\
\hline Water & 300 & 390 & 390 & 390 \\
\hline FA1 & - & 175 & - & - \\
\hline FA2 & - & - & 175 & - \\
\hline ESP & - & - & - & 175 \\
\hline
\end{tabular}




\section{Results and discussion}

The chemical composition of fly ashes determined by XRF is summarized in Table 2. It has to be noticed that XRF is just a semi-quantitative technique; hence the results have to be taken into account just as indicative (an error as high as $20 \%$ may be estimated). In the Table 2 are presented just contents of major elements; beyond them the ashes contain lot of minor components - metals as well as organics. These minor components bring the well known environmental risks related to MSWI but this topic is not matter of this contribution.

Table 2: Chemical composition of fly ashes determined by XRF (in mass \%).

\begin{tabular}{|c|c|c|c|}
\hline \multirow{2}{*}{ Component } & \multicolumn{3}{|c|}{ mass \% } \\
\cline { 2 - 4 } & FA1 & FA2 & ESP \\
\hline $\mathrm{SiO}_{2}$ & 15.9 & 19.6 & 9.9 \\
\hline $\mathrm{Al}_{2} \mathrm{O}_{3}$ & 8.0 & 9.7 & 4.2 \\
\hline $\mathrm{Fe}_{2} \mathrm{O}_{3}$ & 2.9 & 3.4 & 1.9 \\
\hline $\mathrm{CaO}$ & 25.7 & 25.6 & 13.0 \\
\hline $\mathrm{MgO}$ & 2.1 & 2.4 & 1.2 \\
\hline $\mathrm{SO}$ & 28.8 & 14.9 & 15.7 \\
\hline $\mathrm{ZnO}$ & 2.8 & 2.5 & 8.0 \\
\hline $\mathrm{Na}_{2} \mathrm{O}$ & 5.4 & 5.9 & 17.9 \\
\hline $\mathrm{K}_{2} \mathrm{O}$ & 4.4 & 4.4 & 8.4 \\
\hline $\mathrm{TiO}_{2}$ & 1.6 & 1.6 & 0.8 \\
\hline $\mathrm{Cl}^{2}$ & 0.7 & 7.3 & 15.1 \\
\hline$\sum$ & 98.1 & 97.5 & 96.0 \\
\hline
\end{tabular}

The studied MSWI fly ashes contains hydraulic oxides which are taking part in the hydration reactions $\left(\mathrm{SiO}_{2}, \mathrm{Al}_{2} \mathrm{O}_{3}, \mathrm{Fe}_{2} \mathrm{O}_{3}\right)$ but in lower amounts than it is usual in coal ashes. The critical is, from the point of view of civil engineering, the high content of $\mathrm{SO}_{3}$ - sulphates in the ashes. Other critical point is zinc which is known as hydration retarder. Finally, the ESP fly ash contains very high amount of chlorides which are dangerous, beyond hydration, also for possible steel reinforcement. Noticeable is also high content of alkali metals. The boiler fly ashes FA1 and FA2 are pozzolanic active [12].

The particle size distribution of the fly ashes was measured by conventional way (grading analysis, Figure 1) as well as by particle size analyser (Figure 2). The results for all three fly ashes were rather similar; none of the ashes fulfilled the standard requirements for ashes utilized as concrete admixture [13, 14]. The difference in results which provided two used methods (according to grading analysis size of most of the particles lie between 100 and $1000 \mu \mathrm{m}$ while the 
laser analysis reported prevailing particles diameter 1-200 $\mu \mathrm{m}$ ) can be explain by tendency of ash particles to form aggregates (Figure 3). These aggregates behave like large particles when undergo grading analysis but the ultrasonic disintegrator breaks them in the laser analyser. Hence the laser analyser reports the real particle size while the sieving analysis corresponds to the size of particles aggregates. The agglomeration of all ashes was observed by SEM as well.

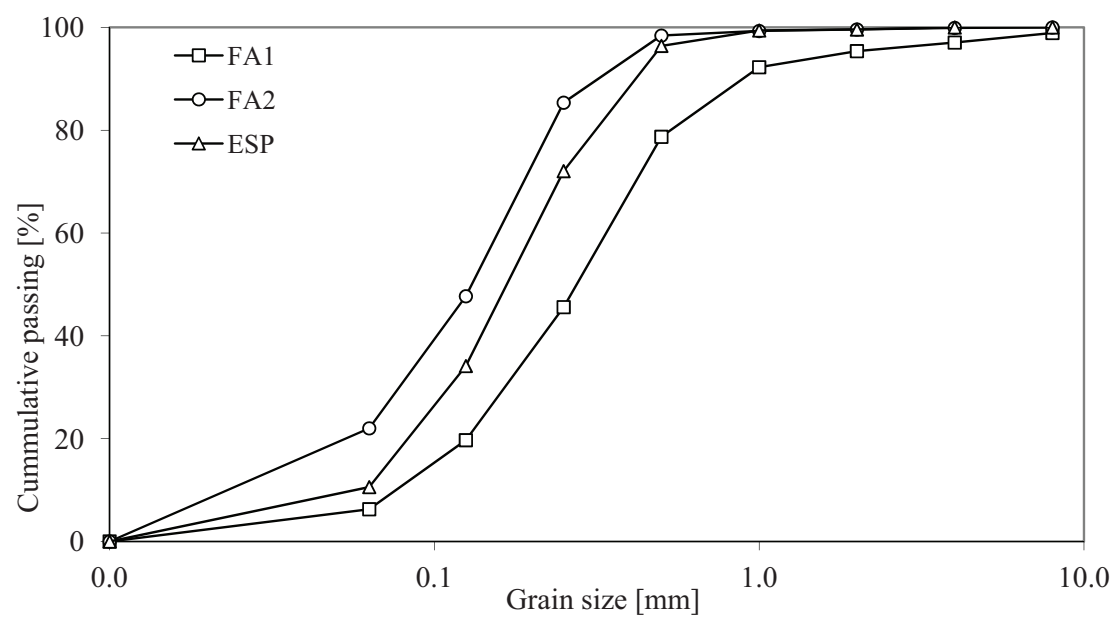

Figure 1: Grading curves of MSWI fly ashes measured by sieves.

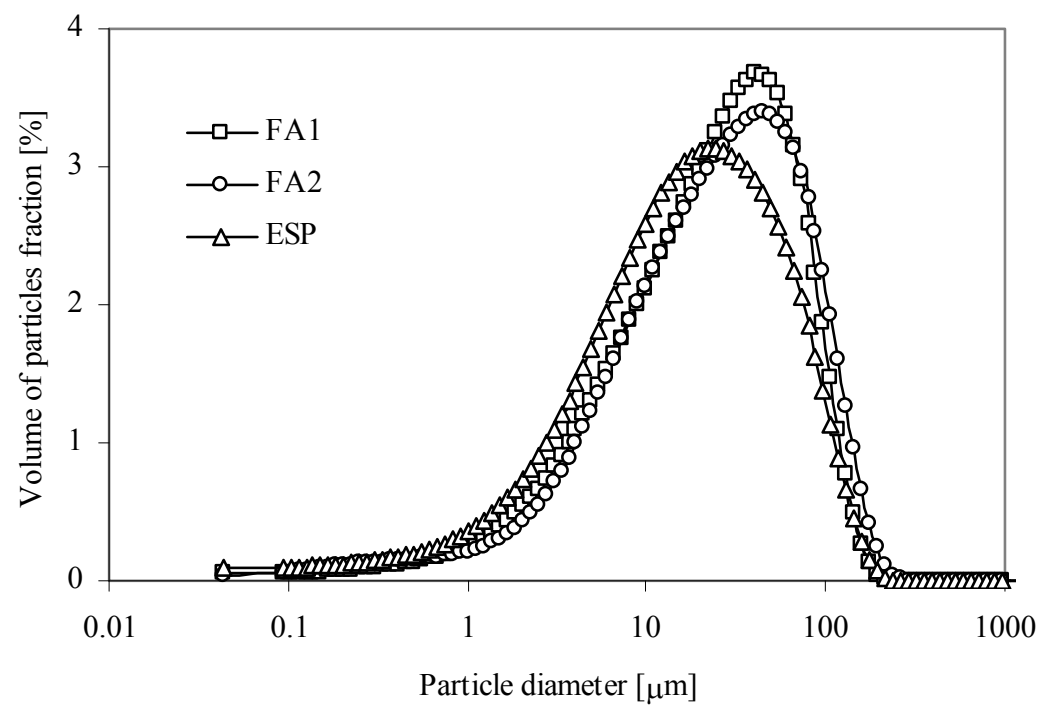

Figure 2: $\quad$ Particle size distribution of fly ashes. 


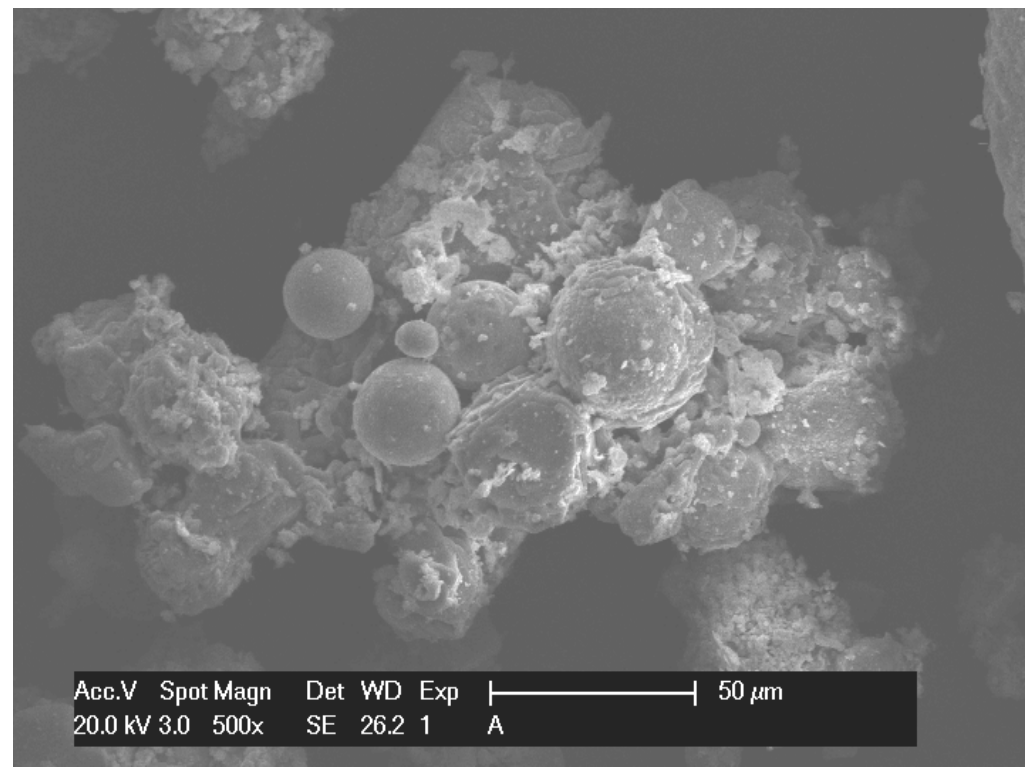

Figure 3: $\quad$ SEM micrograph of aggregated particles (FA1).

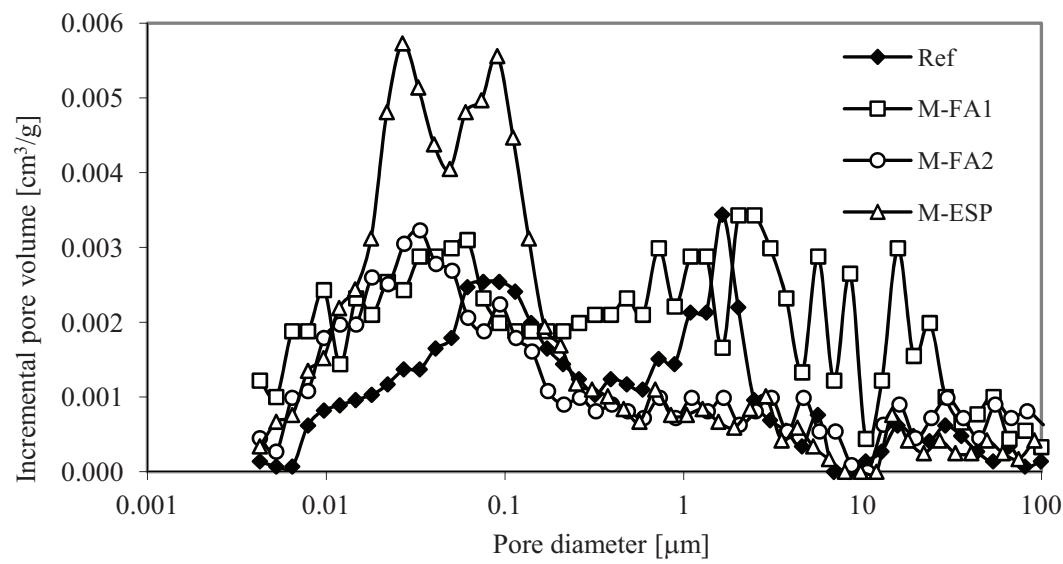

Figure 4: $\quad$ Pore size distribution of studied mortars.

The added fly ashes increased porosity of mortars (Table 3). Especially the boiler fly ash FA1 caused high porosity what can be explained by high content of sulphates in this ash. The pore size distribution (Figure 4) illustrated the effect of particular ashes on the pore system. The ESP and FA2 fly ashes influenced entirely the gel pores (to diameter $0.1 \mu \mathrm{m}$ ) while the FA1 caused increase of volume of all pores - both gel and capillary. 
Table 3: $\quad$ Basic physical properties of studied mortars.

\begin{tabular}{|c|c|c|c|}
\hline Material & Porosity & Bulk density & Apparent density \\
\hline & $\%$ & $\mathrm{~kg} / \mathrm{m}^{3}$ & $\mathrm{~kg} / \mathrm{m}^{3}$ \\
\hline Ref & 11.4 & 2.15 & 2.43 \\
\hline M-FA1 & 19.4 & 1.95 & 2.41 \\
\hline M-FA2 & 12.8 & 2.17 & 2.49 \\
\hline M-ESP & 16.0 & 2.01 & 2.40 \\
\hline
\end{tabular}

The effect of fly ashes on strength was evaluated by means of standard measurement of bending and compressive strength on prismatic specimens (Figure 5). The M-ESP sample had practically the same strength as the reference mortar. The boiler fly ashes reduced the strength in a significant extent. Noticeable is fact that while the compressive strength was reduced by ashes, the bending strength remained unaffected.

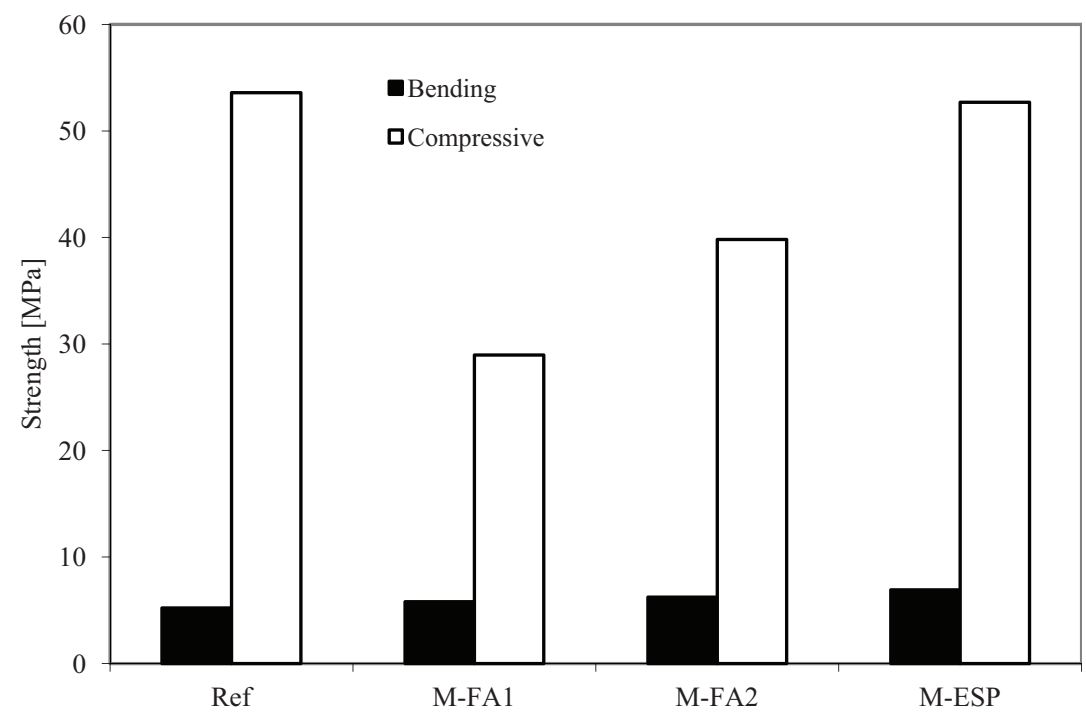

Figure 5: Bending and compressive strength of prepared mortars.

Similar pattern of behaviour as in the case of strength featured the mortars also in case of durability (Figure 6). The freezing/thawing action reduced the compressive strength of the reference mortar to approximately half of the initial (unloaded) value. The same behaviour was observed in case of mortar M-ESP. The strength of M-FA2 decreased to 1/3. The mortar containing boiler ash FA1 disintegrated completely after 75 freezing/thawing cycles thus its strength was not measured. 


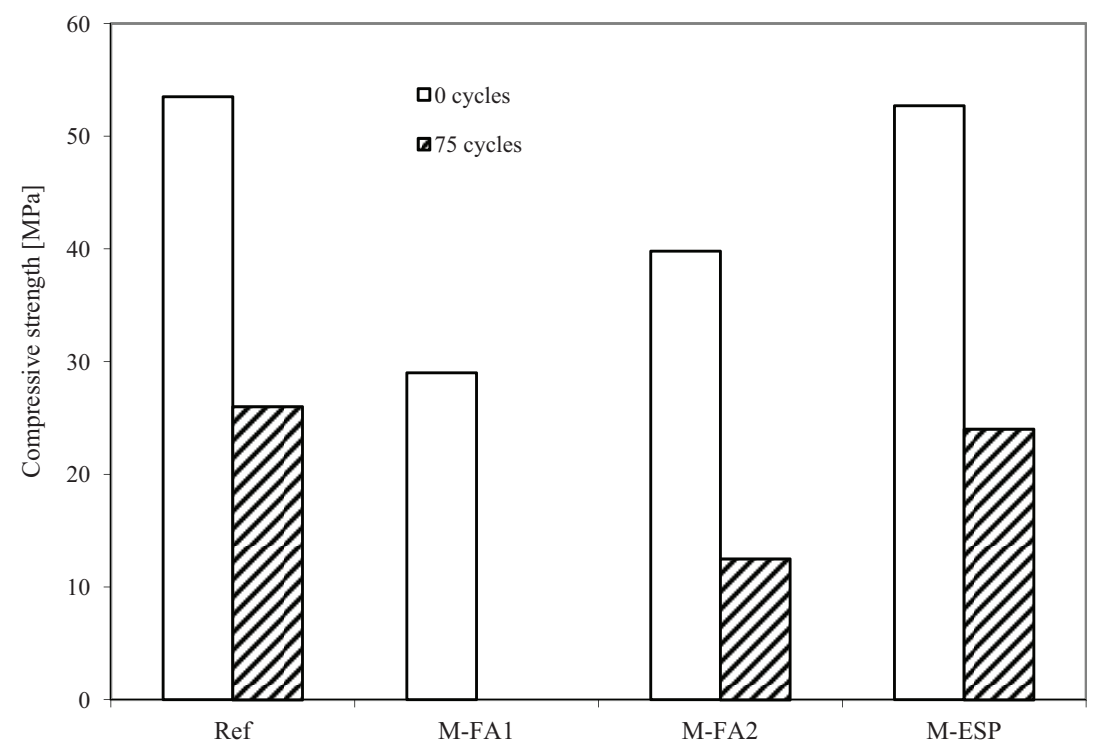

Figure 6: Compressive strength of prepared mortars before and after 75 freezing/thawing cycles.

The presented results revealed that the individual fly ashes differ significantly in their behaviour even though they are produced in one plant. The different behaviour was obviously caused by highly different chemical composition. The crucial seems to be high concentration sulphates in FA1. Sulphates form expansive products - ettringite and gypsum which increase the porosity of material and weaken its strength (due to increase of porosity and also decrease of $\mathrm{CAH}$ and CSH content) and durability. The other ashes FA2 and ESP contain high (unacceptable from the point of view of concrete technical standards) amounts of sulphates as well but evidently the behaviour of mortars containing these two ashes is not so prospectless as in the case of FA1. The reason can be found in the way how the ashes influence the character of pore system. FA1 is the only fly ash which causes increase of amount/volume of capillary pores. These "FA1-induced" pores increase the mortars absorptivity and the rate of water transport what results into decrease of durability.

The presented results indicate promising behaviour of ESP fly ash. Unfortunately the high content of chlorides and zinc cause significant increase of initial and final setting time of materials containing this ESP fly ash [15]. Nevertheless the moderate dosage of ESP fly ash will not affect the mortars properties dramatically.

\section{Conclusions}

Three kinds of fly ashes generated in a single MSWI facility were tested as potential partial replacement of natural sand in cementitious materials. The 
motivation was to recycle the MSWI wastes and reduce the natural resources consumption. It was found that the effect of ashes on the prepared mortars depends on chemical compositions of particular fly ashes. The granulometry of the ashes is very similar; the ashes tend to form aggregates. Relatively lowest negative effect on mechanical and durability properties had the ESP fly ash but it had negative effect on setting time. The worse performance exhibited boiler fly ash FA1 with the highest sulphates concentration. This fly ash causes increase of capillary pores volume in the prepared material which leads to its lower durability.

The utilization of studied fly ashes in concrete production is possible but it is accompanied with decrease of the concrete properties. The solution lies in a treatment procedure which will reduce content of dangerous components in ashes. The simplest is the water washing which reduces the chloride content and could solve the problems of ESP fly ash [16]. The other in literature proposed way - the vitrification of fly ashes - is technologically and energetically unfavored.

\section{Acknowledgements}

This research has been supported by the Czech Science Foundation, under project No. P104/11/0438 and by the Ministry of Education, Youth and Sports of the Czech Republic, under the project No. MSM: 6840770031.

\section{References}

[1] Pera, J., Coutaz, L., Ambroise, J., Chababbet, M.: Use of Incinerator Bottom Ash in Concrete. Cement and Concrete Research. 27, pp. 1-5, 1997.

[2] Lin, K. L., Wang, K. S., Tzeng, B. Y., Lin, C. Y.: The Reuse of Municipal Solid Waste Incinerator Fly Ash Slag as a Cement Substitute. Resources Conservation \& Recycling. 39, pp. 315-324, 2003.

[3] Aubert, J.E., Husson, B., Vaquier, A.: Use of Municipal solid waste incineration fly ash in concrete. Cement and Concrete Research, 34, pp. 957-963, 2004.

[4] Müller, U., Rübner, K.: The Microstructure of Concrete Made with Municipal Waste Incinerator Bottom Ash as an Aggregate Component. Cement and Concrete Research, 36, pp. 1434-1443, 2006.

[5] Gao, X.B., Wang, W., Ye, T.M., Wang, F., Lan, Y.X.: Utilization of washed MSWI fly ash as partial cement substitute with the addition of dithiocarbamic chelate. Journal of Environmental Management, 88, pp. 293-299, 2008.

[6] Lee, T.C., Rao M.K.: Recycling municipal incinerator fly- and scrubber-ash into fused slag for the substantial replacement of cement in cement-mortars. Waste management, 29, pp. 1952-1959, 2009. 
[7] Lee, T.C., Li, Z.S.: Conditioned MSWI ash-slag-mix as a replacement for cement in cement mortar. Construction and Building materials, 24, pp. 970979, 2010.

[8] ČSN EN 933-2, Tests for geometrical properties of aggregates. Determination of particle size distribution. Test sieves, nominal size of apertures. Czech Standardization Institute, 1997.

[9] CSN EN 12 390-5, Testing hardened concrete. Flexural strength of test specimens. Czech Standardization Institute, 2007.

[10] ČSN EN 12 390-3, Testing hardened concrete. Compressive strength of test specimens. Czech Standardization Institute, 2002.

[11] CSN 73 722, Concrete frost resistance. Czech Standardization Institute, 1968 (change 2003).

[12] Keppert, M., Tydlitát, V., Volfová, P., Šyc, M., Černý, R.: Characterization of Solid Waste Materials Produced by a Modern Municipal Solid Waste Incineration Facility from the Point of View of Civil Engineering. Proceedings of the Second International Conference on Sustainable Construction Materials and Technologies, Ancona, 2010.

[13] EN 12620, Aggregates for concrete. European Committee for Standardization, 2002.

[14] EN 450-1, Fly ash for concrete. Definition, specifications and conformity criteria. European Committee for Standardization, 2005.

[15] Keppert, M., Reiterman, P., Pavlík, Z., Pavlíková, M., Jerman, M., Černý, R.: Municipal solid waste incineration ashes and their potential for partial replacement of Portland cement and fine aggregates in concrete. Cement Wapno Beton, 15/77, pp. 187-193, 2010.

[16] Bertolini, L., Carsana, M., Cassago, D., Curzio, A. Q., Collepardi, M. MSWI ashes as mineral additions in concrete. Cement and Concrete Research, 34, pp. 1899-1906, 2004. 